\title{
Mechanical stretch and LPS affect the proliferation, extracellular matrix remodeling and viscoelasticity of lung fibroblasts
}

\author{
YONGPENG XIE $^{1 *}$, YING QIAN $^{1 *}$, YANLI WANG $^{2}, \mathrm{KEXI} \mathrm{LIU}^{1}$ and XIAOMIN LI ${ }^{2}$ \\ Departments of ${ }^{1}$ Critical Care Medicine and ${ }^{2}$ Emergency Medicine, Lianyungang Clinical College of \\ Nanjing Medical University, The First People's Hospital of Lianyungang, Lianyungang, Jiangsu 222000, P.R. China
}

Received June 5, 2019; Accepted February 18, 2020

DOI: $10.3892 /$ etm.2020.9133

\begin{abstract}
The present study aimed to investigate the effects of mechanical stretch and lipopolysaccharides (LPS) on the expression of transforming growth factor- $\beta 1$ (TGF- $\beta 1$ ) and collagen and viscoelasticity in human embryonic MRC-5 lung fibroblasts cultured in vitro and to assess the mechanisms of ARDS-associated ventilator-induced lung injury using an in vitro model. Human embryonic MRC-5 lung fibroblasts were treated with different concentrations of LPS to establish an acute respiratory distress syndrome (ARDS) cell injury model, followed by further culture under different mechanical stretch amplitudes using the Flexcell system to establish a cellular mechanical damage model. The proliferation of MRC-5 cells and the protein and gene expression levels of TGF- $\beta 1$ and collagen were detected by flow cytometry, ELISA and reverse transcription-quantitative PCR, respectively. As the concentration of LPS increased, the proliferation activity of MRC-5 cells gradually decreased. Low concentrations of LPS led to upregulation of the secretion levels of TGF- $\beta 1$ and collagen I and the expression of their mRNA, TGF- $\beta 1$ mRNA and collagen type $1, \alpha 1$. Conversely, high concentrations of LPS reduced TGF- $\beta 1$ and collagen I levels and their gene expression. Mechanical stimulation with a stretch of $5 \%$ increased the cell proliferation activity; however, it had no significant effect on the expression levels of TGF- $\beta 1$ and collagen. Mechanical stimulation with a stretching force of $10 \%$ inhibited the cell proliferation but increased the expression levels of TGF- $\beta 1$ and collagen I. A higher mechanical stimulation (15 and 20\%) had a significantly greater effect. Mechanical stretch and LPS stimulation led to
\end{abstract}

Correspondence to: Dr Xiaomin Li, Department of Emergency Medicine, Lianyungang Clinical College of Nanjing Medical University, The First People's Hospital of Lianyungang, 6 Zhenhua Road, Lianyungang, Jiangsu 222000, P.R. China

E-mail: lyglxm1@163.com

*Contributed equally

Key words: mechanical stretch, lipopolysaccharide, human embryonic lung fibroblasts, transforming growth factor- $\beta 1$, collagen, pulmonary structural remodeling changes in the structure and viscoelastic behavior of human embryonic MRC-5 lung fibroblasts. In terms of cell function, mechanical stretch may cause an increase in the expression of TGF- $\beta 1$ in MRC- 5 cells, in turn affecting the transcription and translation of collagen genes. This present study provides provides cell-level evidence for understand the mechanisms of action behind the ARDS ventilator-induced lung injury and lung structural remodeling.

\section{Introduction}

Acute respiratory distress syndrome (ARDS) has always been a controversial topic in medical research due to its high incidence and high risk/rate of mortality. Mechanical ventilation has a key role in the treatment of patients with ARDS (1). However, mechanical ventilation may cause ventilator-induced lung injury (VILI) and cause or accelerate pulmonary fibrotic changes (2). A previous study indicated that the severity of pulmonary fibrosis is closely linked to mortality, prognosis and long-term quality of life in patients with ARDS (3). However, the mechanism has remained to be completely clarified and there is still a lack of effective prevention and treatment measures in clinical settings (4). Studies have suggested a close association of mechanical stimulation, transforming growth factor $\beta 1$ (TGF- $\beta 1)$ and collagen with lung tissue remodeling in $\operatorname{ARDS}(5,6)$, but the regulatory mechanism has remained elusive. In the present study, MRC-5 human embryonic lung fibroblasts were treated with lipopolysaccharides (LPS) at the cellular level to establish an ARDS cell injury model and the cells were further cultured with different mechanical stretching amplitudes through the Flexcell system to establish a cellular mechanical damage model. The protein and gene expression levels of TGF- $\beta 1$ and collagen were detected by ELISA and reverse transcription-quantitative (RT-q) PCR, respectively, and the viscoelastic behavior of human embryonic lung fibroblasts under LPS and mechanical stretch stimulation was further explored. The present study supported the notion that in patients with mechanical ventilation, mechanical stretch aggravates ARDS-associated lung injury and promotes lung structural remodeling. It provided underlying mechanobiological mechanisms and guidance for early prevention and treatment of ventilator-induced lung injury and pulmonary structural remodeling during ARDS treatment. 


\section{Materials and methods}

Cell lines and reagents. The human embryonic lung fibroblast cell line, MRC-5 (Cell Bank of Type Culture Collection, Chinese Academy of Sciences), was maintained in minimal essential medium (Invitrogen; Thermo Fisher Scientific, Inc.) which contained $2.0 \mathrm{mmol} / 1$ glutamine. The medium was supplemented with $10 \%$ fetal calf serum (Invitrogen; Thermo Fisher Scientific, Inc.) and cells were cultured at $37^{\circ} \mathrm{C}$ in a humidified atmosphere containing 5\% carbon dioxide and $95 \%$ air. The MRC-5 cells were inoculated on a flexible substrate culture plate (FX-5000, Flexcell International Corp.). MRC-5 cells in the logarithmic growth phase were cultured for $48 \mathrm{~h}$ with different concentrations of LPS $(0,5,20$ or $50 \mu \mathrm{g} / \mathrm{ml})$. Subsequently, different amplitudes of mechanical stretch stimulation were applied to the cells via the Flexcell loading system (Flexcell Corp., USA) and culture was continued for $48 \mathrm{~h}$ (loading parameters: Frequency, $0.1 \mathrm{~Hz}$; sine wave, stretching amplitude of 5, 10, 15 and 20\%).

Detection of cell proliferation. MRC-5 cells were collected after LPS stimulation and/or mechanical stretch treatment. The cells were labeled with carboxyfluorescein succinimidyl ester (CFSE) and cell proliferative activity was assessed by flow cytometry (BD FACSCalibur; BD Biosciences). CFSE is a non-toxic dye for cells and its chemical properties are stable. Once CFSE enters the cell, it cannot be released from the cell and will not be metabolized. The only way to reduce the CFSE content in cells is through cell proliferation and division. The CFSE contained in the cells enters the progeny cells as the cells proliferate. The cells were labeled with CFSE before inoculation on a flexible substrate culture plate where the initial fluorescence intensity was measured. Subsequently, the fluorescence intensity after proliferation was measured after LPS stimulation and/or mechanical stretch treatment by flow cytometry. To determine the proliferative activity of chondrocytes, the proliferation index was calculated as follows: Proliferation index=initial fluorescence intensity/fluorescence intensity after proliferation.

Detection of protein expression levels. MRC-5 cells were treated by LPS stimulation and/or mechanical stretch for $48 \mathrm{~h}$. The supernatant was collected after centrifugation $(503.1 \mathrm{x} \mathrm{g}$ for $5 \mathrm{~min}$ at $25^{\circ} \mathrm{C}$ ) to remove impurities and refrigerated at $-70^{\circ} \mathrm{C}$. An ELISA kit (1R443; Rapidbio) was used according to the manufacturer's protocol. The absorbance at $450 \mathrm{~nm}$ was detected with a microplate reader (iMark; Bio-Rad Laboratories, Inc.) and the content of TGF- $\beta 1$ in the sample was extrapolated by using a standard curve.

Detection of gene expression levels. TRIzol ${ }^{\circledR}$ reagent (Invitrogen; Thermo Fisher Scientific, Inc.) was used to extract total RNA from from the control and treated MRC-5 cells and reverse transcribe RNA into cDNA. The expression of TGF- $\beta 1$ mRNA and collagen type I $\alpha 1$ (Coll $\alpha 1)$ mRNA in human embryonic lung fibroblasts were detected by RT-qPCR (7). The PCR detection was determined using an Exicycler ${ }^{\mathrm{TM}}$ 96 real-time system (Bioneer) with SYBR Premix ExTaqII (Takara Bio, Inc.). The PCR conditions were as follows: Enzyme activation at $94^{\circ} \mathrm{C}$ for $5 \mathrm{~min}$, amplification at $94^{\circ} \mathrm{C}$ for $10 \mathrm{sec}$, annealing at $60^{\circ} \mathrm{C}$ for $20 \mathrm{sec}$ and extension at $72^{\circ} \mathrm{C}$ for $30 \mathrm{sec}, 40$ cycles, final extension at $72^{\circ} \mathrm{C}$ for $6 \mathrm{~min}$. The expression level of the target genes, TGF- $\beta 1$ and Coll $\alpha 1$, were quantified using the $2^{-\Delta \Delta C q}$ method (7). $\beta$-actin was used as a reference gene. The primers were as follows: $\beta$-actin forward, 5'-GACAGGATGCAGAAGGAGATTACT-3' and reverse, 5'-TGATCCACATCTGCTGGAAGGT-3', TGF- $\beta 1$ forward, 5'-GCCCTGGACACCAACTATTGC-3' and reverse, 5'-AGG CTCCAAATGTAGGGGCAG-3'; Coll $\alpha 1$ forward, 5'-GCC TAGCAACATGCCAATC-3' and reverse, 5'-GCAAAGTTC CCACCGAGA-3'.

Micropipette aspiration and viscoelasticity calculation. The deformation of control and treated MRC-5 cells under the negative pressure (range from 0.245 to $0.392 \mathrm{kPa}$ ) were examined using a micropipette aspiration system, which produced the association between aspirated lengths and time (8-10). The cellular viscoelastic parameters [the instantaneous modulus $\left(E_{0}\right)$, the equilibrium modulus associated with long-term equilibrium $\left(E_{\infty}\right)$ and the apparent viscosity $(\mu)$ ] were calculated using the Kelvin standard linear viscoelastic solid model as previously described, and the cellular viscoelastic parameters $\left(E_{0}, E_{\infty}\right.$ and $\left.\mu\right)$ were calculated according to the association between aspirated lengths and time (8-10). The viscoelastic model and a cell sucked in by the microtubules are shown in Fig. 1.

Statistical analysis. In the present study, all the independent experiments were repeated three times. Data processing and mapping were performed using SPSS 22.0 statistical software (IBM Corp.) and GraphPad Prism 6.0 (GraphPad Software, Inc.). The measurement data were expressed as the mean \pm standard deviation. Differences between the groups were compared by one-way analysis of variance with the Student-Newman-Keuls post-hoc test. $\mathrm{P}<0.05$ was considered to indicate a statistically significant difference.

\section{Results}

Effect on MRC-5 cell proliferation activity. MRC-5 cells were treated with different concentrations of LPS and the cell proliferation activity was analyzed by flow cytometry. It was indicated that LPS induced cell damage and decreased the proliferative activity. As the concentration of LPS increased, the cell proliferation activity continued to significantly decrease ( $\mathrm{P}<0.01$; Fig. $2 \mathrm{~A})$. MRC-5 cells were cultured under different stretch amplitudes and the cell proliferation activity was analyzed by the same method. The results suggested that the proliferative activity of MRC-5 cells cultured under a low-amplitude stretch (5 and 10\%) was significantly increased, but as the stretch amplitude increased (15 and 20\%), the proliferative activity of MRC-5 cells exhibited a significant decrease $(\mathrm{P}<0.01$; Fig. 2B). According to the experimental results obtained with different concentrations of LPS combined with clinical practice to simulate ARDS induced injury, cells treated with LPS at low concentrations $(5 \mu \mathrm{g} / \mathrm{ml})$ were selected to construct a cell injury model similar to the pathophysiological state of ARDS, and culture was then continued at different stretch widths to observe the effects on the proliferative activity. 

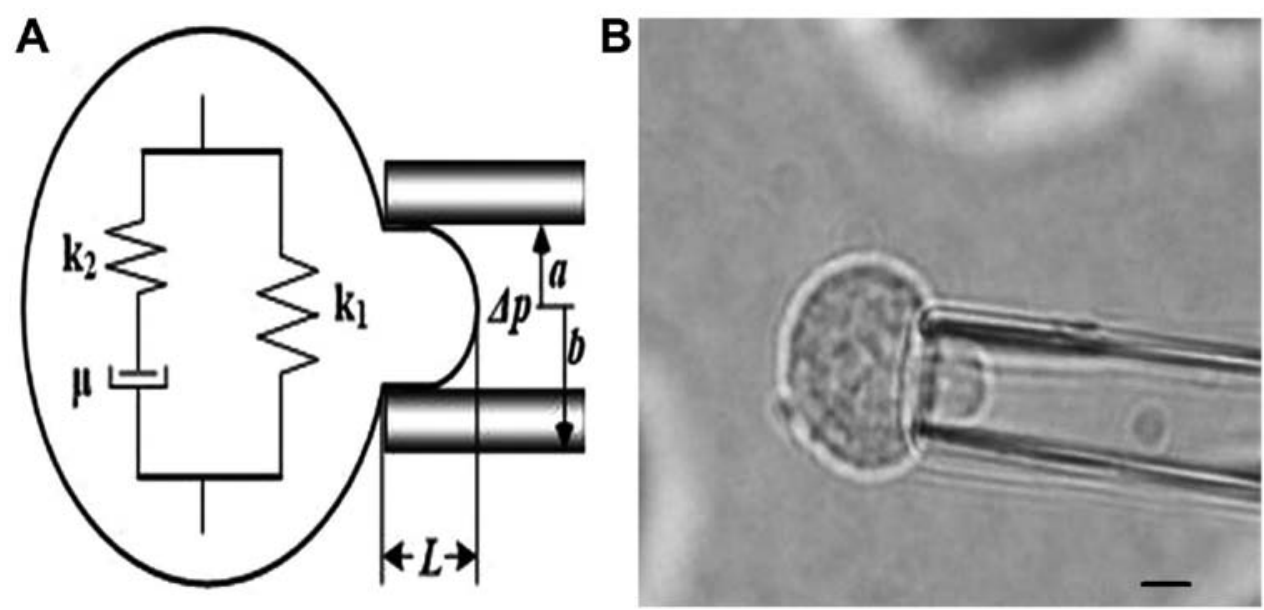

Figure 1. (A) Schematic representation of a standard linear viscoelastic model. (B) Demonstration of a cell being sucked into the microtubules. The scale bar represents $5 \mu \mathrm{m}$.
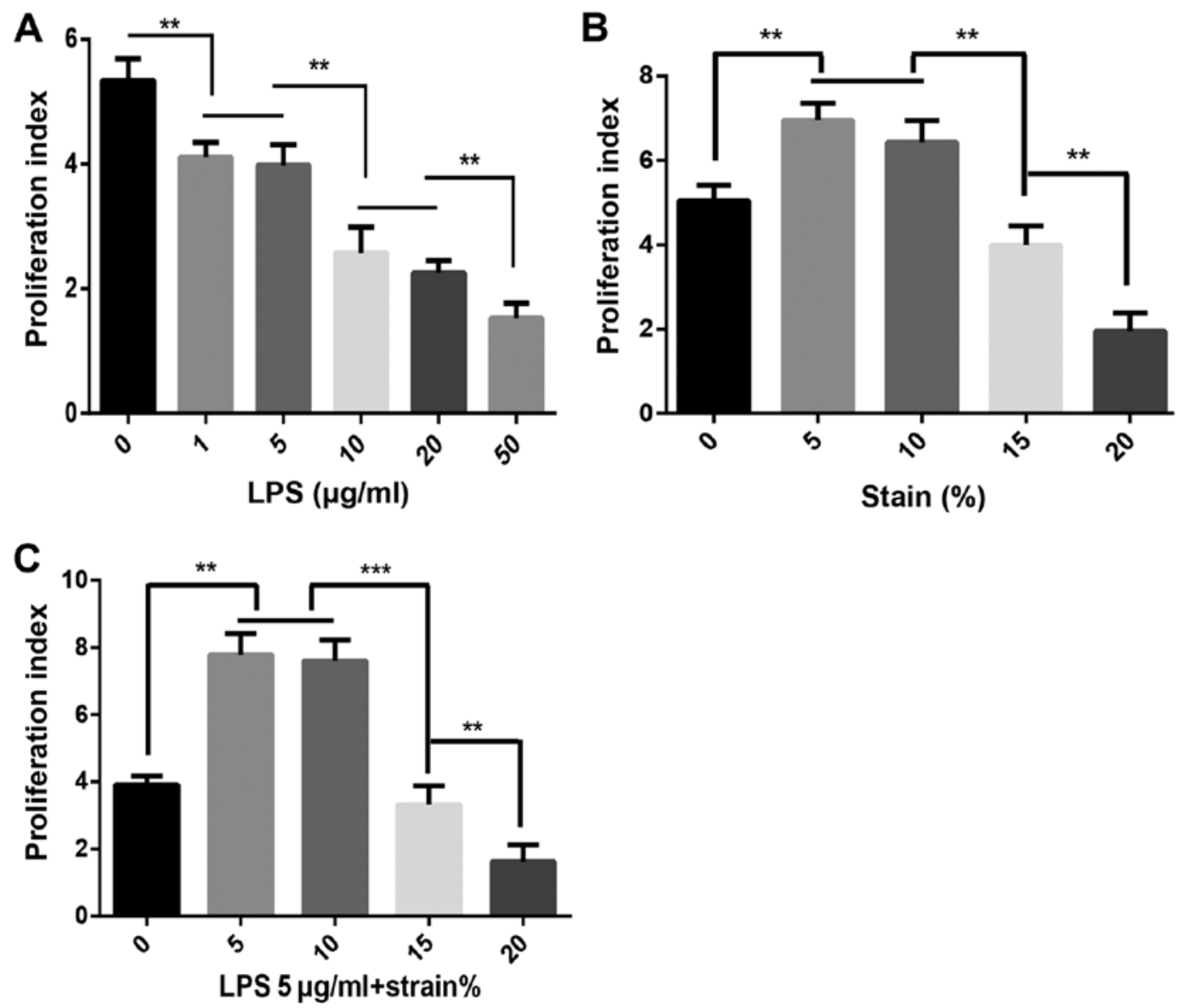

Figure 2. MRC-5 cell proliferation at (A) different concentrations of LPS, (B) different stretch amplitudes and (C) combination of strain and LPS (5 $\mu \mathrm{g} / \mathrm{ml})$. ${ }^{* *} \mathrm{P}<0.05,{ }^{* * *} \mathrm{P}<0.001$. LPS, lipopolysaccharide.

The results also indicated that the proliferation activity of MRC-5 cells stimulated by LPS cultured with a low-amplitude stretch (5 and 10\%) was improved; however, under high traction (15 and 20\%), the cell proliferation was significantly decreased $(\mathrm{P}<0.05$; Fig. 2C).

TGF- $\beta 1$ and collagen I expression by MRC-5 cells following LPS stimulation. As provided in Fig. 3, it was indicated that low concentrations of LPS upregulated TGF- $\beta 1$ and collagen I expression after cell injury, while high concentrations of LPS affected the cell proliferation activity and reduced the expression of TGF- $\beta 1$ and collagen I in the supernatant (Fig. 3A and C). The RT-qPCR results suggested that low concentrations of LPS led to upregulated expression of TGF- $\beta 1$ and Coll $\alpha 1$ mRNA, while high concentrations of LPS decreased their expression (Fig. 3B and D). 

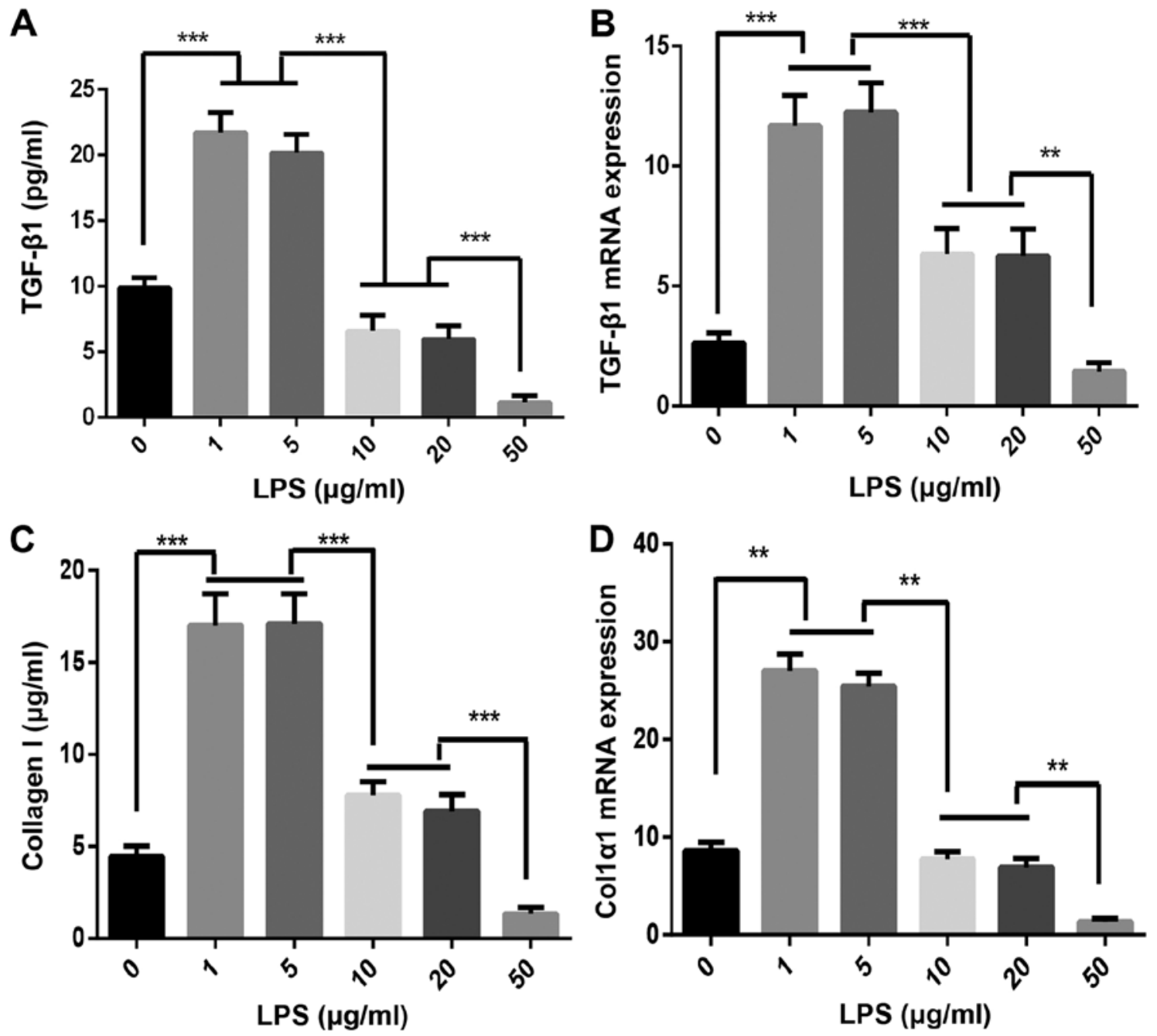

Figure 3. Levels of (A) TGF- $\beta 1$ protein and (B) TGF- $\beta 1 \mathrm{mRNA}$, (C) collagen I protein and (D) Col1 $\alpha 1 \mathrm{mRNA}$ in MRC-5 cells treated with different concentrations of LPS. Data are expressed as the mean \pm standard deviation $(n=6),{ }^{* *} \mathrm{P}<0.05,{ }^{* * *} \mathrm{P}<0.001$. LPS, lipopolysaccharide; TGF, transforming growth factor; Coll $\alpha 1$, collagen type I $\alpha 1$.

TGF- $\beta 1$ and collagen I expression by MRC-5 cells after mechanical stretch stimulation. MRC-5 cells were cultured under different mechanical stretches and the concentration of TGF- $\beta 1$ and collagen in the cells or supernatant was detected (Fig. 4). The results indicated that mechanical stimulation with a stretch of $5 \%$ had no effect on the protein levels of TGF- $\beta 1$ and collagen I, while a $10 \%$ stretch induced a significant increase in TGF- $\beta 1$ and collagen I levels, and a much greater mechanical stimulation (15 and 20\%) significantly increased the levels of TGF- $\beta 1$ and collagen I than the 10\% stretch (Fig. 4A and C). Total RNA was extracted from the control and mechanical stretch-treated MRC-5 cells, and the expression of TGF- $\beta 1$ and Coll $\alpha 1$ mRNA was detected by RT-qPCR. Mechanical stimulation with a stretch of $10 \%$ induced upregulation of TGF- $\beta 1$ and Col1 $\alpha 1$ mRNA expression and a much larger mechanical stretch stimulation (15 and $20 \%$ ) significantly increased the expression of TGF- $\beta 1 \mathrm{mRNA}$ and Coll $\alpha 1$ mRNA in the cells (Fig. 4B and D).

TGF- $\beta 1$ and collagen I expression by MRC-5 cells following combined stimulation with LPS and mechanical stretch. MRC-5 cells were treated with LPS at $5 \mu \mathrm{g} / \mathrm{ml}$ to construct the cell injury model and those cells were cultured for a further $48 \mathrm{~h}$ under mechanical stimulation with different stretch amplitudes. The results indicated that mechanical stimulation with a stretch amplitude of up to $10 \%$ did not result in any significant increase in TGF- $\beta 1$ or collagen I protein, or their gene expression levels in cells following culture with $5 \mu \mathrm{g} / \mathrm{ml}$ LPS ( $>0.05)$. However, much larger mechanical stimulation (15 and 20\%) caused further damage to the LPS cell injury model. At the same time, the levels of TGF- $\beta 1$ and collagen I, and their gene expression levels were significantly increased $(\mathrm{P}<0.05$; Fig. 5).

Viscoelastic changes of MRC-5 cells under different mechanical stimulation. MRC-5 cells treated with $5 \mu \mathrm{g} / \mathrm{ml}$ of LPS were cultured under different mechanical stimulation conditions. A cell microtubule suction test indicated that MRC-5 cells exhibited typical viscoelastic solid creep characteristics under constant negative pressure. MRC-5 cells exhibited an instantaneous viscoelastic deformation. The trend of cell inhalation length changing with time at a constant negative pressure of $294 \mathrm{~Pa}$ in each group suggested that LPS stimulation and mechanical stretch treatment increased the 

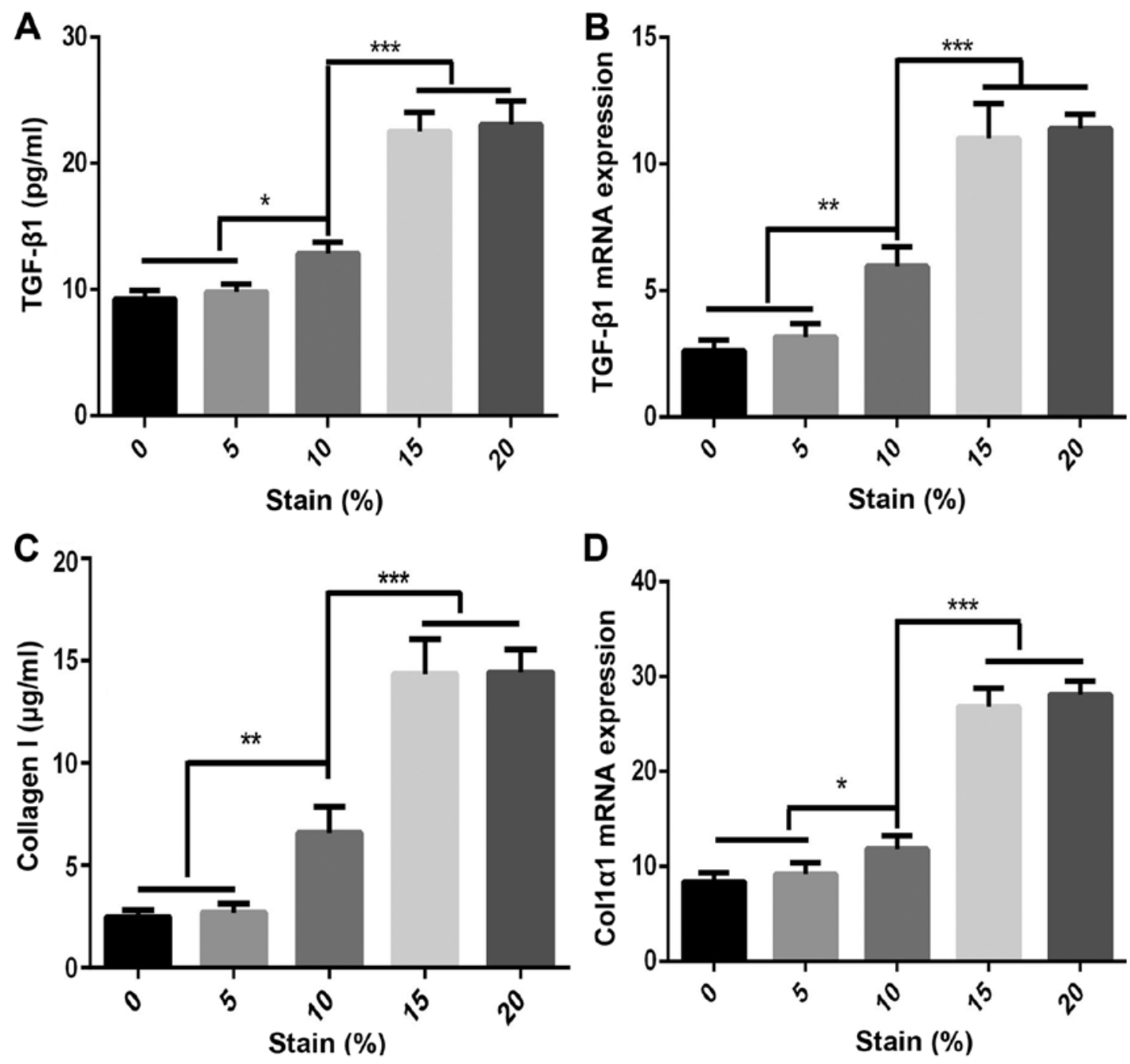

Figure 4. Levels of (A) TGF- $\beta 1$ protein and (B) TGF- $\beta 1$ mRNA, (C) collagen I protein and (D) Col1 $\alpha 1$ mRNA in MRC-5 cells under different mechanical strains. Data are expressed as the mean \pm standard deviation $\left.(\mathrm{n}=6) .{ }^{*} \mathrm{P}<0.05,{ }^{* * *} \mathrm{P}<0.05,{ }^{* * * *} \mathrm{P}<0.001\right)$. TGF, transforming growth factor; Coll $\alpha 1$, collagen type I $\alpha 1$.

inhalation length of cells and the length of inhalation was positively correlated with the stretch amplitude (Fig. 6). The viscoelastic parameters $\left(E_{0}, E_{\infty}\right.$ and $\left.\mu\right)$ of treated and control MRC-5 cells are presented in Fig. 7. The results showed that the LPS treatment significantly reduced all viscoelastic parameters of MRC- 5 cells $(\mathrm{P}<0.05)$. After LPS treatment, the biomechanical properties of MRC- 5 cells were reduced and the cells were softened. A mechanical stretch of $5 \%$ had no effect on the biomechanical properties of MRC-5 cells treated with only $5 \mu \mathrm{g} / \mathrm{ml}$ LPS. As the mechanical stretch increased, the viscoelasticity of MRC-5 cells gradually decreased $(\mathrm{P}<0.05)$, but there was no significant difference in cell viscoelasticity between the two groups of MRC-5 cells cultured with a 15 and $20 \%$ mechanical stretch $(\mathrm{P}>0.05)$.

\section{Discussion}

ARDS is serious common disease of intensive care medicine and the mortality rate is as high as $46 \%$ (11). The use of an ARDS-associated mechanical ventilator is a key treatment of patients with ARDS; however, it may cause ARDS-associated ventilator-induced lung injury and pulmonary fibrosis. A previous study indicated that have indicated that pulmonary fibrosis is closely related to mortality, prognosis and quality of life in patients with ARDS (12). However, to date, the cellular mechanisms of pulmonary fibrosis in patients with ARDS have remained to be clarified and the clinical prevention and treatment effects are not satisfactory. In the present study, an ARDS cell injury model was generated by LPS stimulation of MRC-5 human embryonic lung fibroblasts. Furthermore, mechanical stretch stimulation was performed on MRC-5 cells to study the biomechanical changes of lung fibroblasts during the pathological progression of ARDS-associated pulmonary fibrosis.

TGF- $\beta$ is a class of cytokines with autocrine and paracrine functions, which are considered to be the most critical fibrotic factors. TGF- $\beta$ regulates the expression of effector genes, including collagen, by transducing signals through intracellular signaling molecules (1). The present study indicated that TGF- $\beta 1$ is activated in the early stage of ARDS and participates in the process of lung tissue damage repair. As a potent profibrotic cytokine, it regulates the expression and secretion of collagen in lung tissue (13). The present study indicated that MRC-5 cells treated with different concentrations of LPS expressed different levels of TGF- $\beta 1$ mRNA and Coll $\alpha 1$ mRNA. Cell injury was induced by low concentrations 

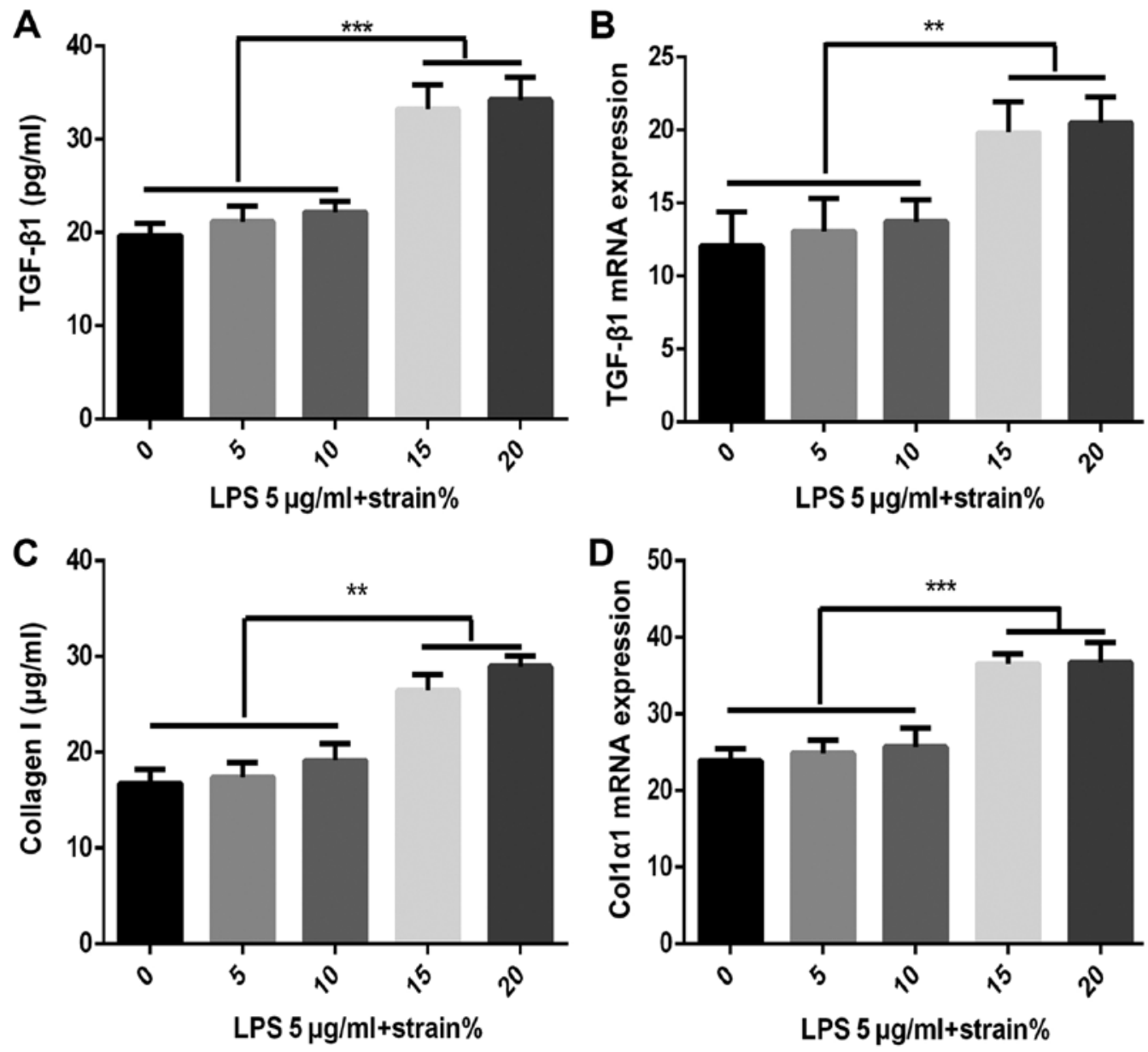

Figure 5. Levels of (A) TGF- $\beta 1$ protein and (B) TGF- $\beta 1 \mathrm{mRNA}$, (C) collagen I protein and (D) Col1 $\alpha 1 \mathrm{mRNA}$ in MRC-5 cells (5 $\mu \mathrm{g} / \mathrm{ml}$ LPS-treated) under different mechanical stretch stimulation. Data are expressed as the mean \pm standard deviation $\left.(\mathrm{n}=6) .{ }^{* * *} \mathrm{P}<0.05,{ }^{* * *} \mathrm{P}<0.001\right)$. LPS, lipopolysaccharide; TGF, transforming growth factor; Col1 $\alpha 1$, collagen type I $\alpha 1$.

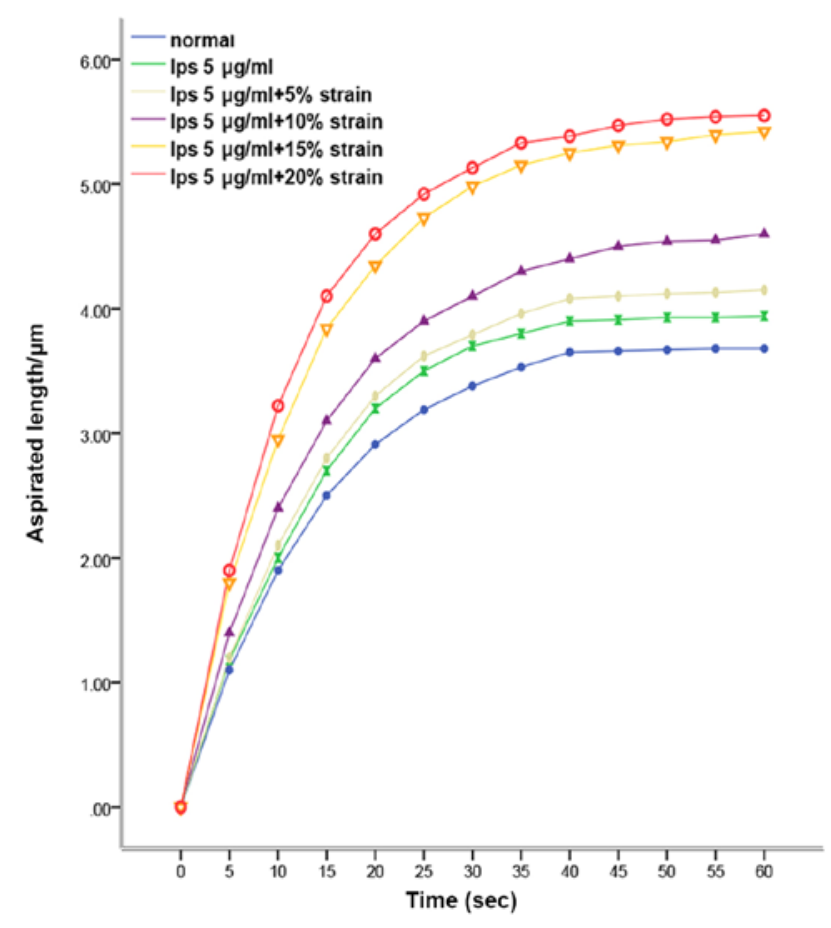

Figure 6. Curves representing MRC-5 cells treated with $5 \mu \mathrm{g} / \mathrm{ml}$ LPS aspirated lengths over time at a constant negative pressure of $30 \mathrm{~mm} \mathrm{H}_{2} \mathrm{O}(\mathrm{n}=1)$. LPS, lipopolysaccharide. of LPS, thereby leading to enhanced expression of TGF- $\beta 1$ and collagen I and promoting the progression of lung fibrosis. High concentrations of LPS affected the cell proliferative activity and altered and destroyed the normal structure of lung fibroblasts, causing serious damage to cells and severely reducing the expression of TGF- $\beta 1$ and collagen I. This may be consistent with the pathophysiological manifestations of clinically severe ARDS cases due to the massive endotoxin release caused by severe infection, which results in severe lung damage. In such cases, patients die due to rapid deterioration of lung function, losing treatment opportunities, but the lungs do not have time to progress to pulmonary fibrosis. This also explains the high mortality rate of ARDS.

The lung is a mechanical organ. Mechanical ventilation causes repeated stress on the lung tissue and exerts mechanical stretch effects on alveolar epithelial cells, lung fibroblasts and pulmonary macrophages (14). In the pathological state of ARDS, different mechanical stretch modes and amplitudes have different molecular biological and cytological effects on lung tissue cells, affecting gene expression and metabolism of cells. Biomechanical signal transduction has a key role in the initiation of mechanical activation of intracellular inflammatory signaling pathways (15). During the mechanical ventilation treatment of ARDS, the connective tissue of the lung continuously withstands and transmits mechanical signals. 

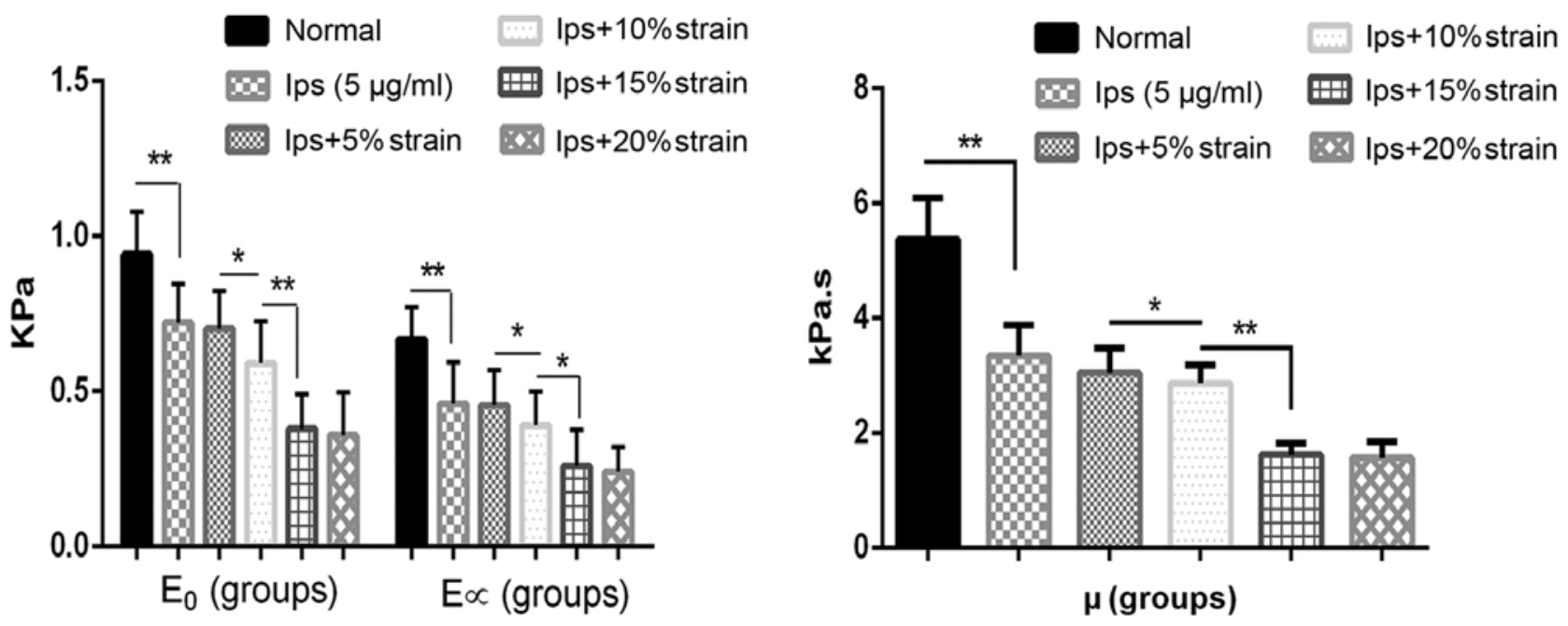

Figure 7. Schematic representation of a standard linear viscoelastic model and comparison of viscoelastic parameters $\left(E_{0}, E_{\infty}\right.$ and $\left.\mu\right)$ of each group. Data are expressed as the mean \pm standard deviation $(n=6) .{ }^{*} \mathrm{P}<0.05,{ }^{* *} \mathrm{P}<0.05$. LPS, lipopolysaccharide.

The fibroblasts of connective tissue are cells that respond to mechanical stretch stimulation. They are able to change their own cellular mechanical characteristics and alter the gene and protein expression of their own extracellular matrix under external physical (e.g. stretch force), chemical (e.g. chemical poisons) and biological (e.g. infectious toxins) factors, maintaining the structure and function of organ tissues $(16,17)$. In the present study, mechanical stimulation at different stretch amplitudes was performed on normal and $5 \mu \mathrm{g} / \mathrm{ml}$ LPS-treated human embryonic lung fibroblasts. The results indicated that appropriate mechanical stimulation is able to increase the proliferative activity of cells and also slightly stimulate the expression of TGF- $\beta 1$ and collagen I in human embryonic lung fibroblasts. Larger mechanical stimulation directly causes cell damage, reduces the cell proliferation activity and induces the expression of TGF- $\beta 1$, which leads to a significant increase in collagen expression and accelerates the process of pulmonary fibrosis.

The present study demonstrated that mechanical stretch is able to regulate multiple functions of lung fibroblasts, including cell proliferation and gene and protein expression. It also indicated that the biomechanical viscoelastic parameters of MRC-5 cells after LPS and mechanical stimulation with different stretch amplitudes were significantly smaller than those of normal cells $(\mathrm{P}<0.05)$. After mechanical stimulation of different stretch amplitudes, the biomechanical properties of MRC- 5 cells are reduced and the lung fibroblasts appear to be 'softened', indicating that lung fibroblasts are deformed in a lower order than the linear stress-strain association. This feature is not a reflection of the specific molecular mechanism but of certain higher structural changes, indicating that the cytoskeleton may have been damaged (18). LPS and excessive mechanical stretch stimulation may re-integrate the structure and stress distribution of cytoskeletal fibers and molecular connections from the cell surface to the nucleus, and the cytoskeletal structure and cell membrane structure may be changed (19). These changes may involve the repair and remodeling of lung tissue by regulating cell surface receptors and extracellular matrix alone or in synergistic action (20). The present study only provided a preliminary assessment of the biomechanical properties of lung fibroblasts in the short-term after LPS and mechanical stretch stimulation. Changes in the composition and structure of the lung fibroblast cytoskeleton during pulmonary fibrosis and the mutual regulation of cell mechanical properties and biological properties require further study.

A major limitation of the present study is the lack of validation of the results in samples from patients with ARDS to confirm the in vitro data. Furthermore, the mechanisms of how mechanical stretch stimulation regulates the remodeling of ARDS lung structure were not sufficiently explored and require further study.

In conclusion, mechanical stimulation may lead to changes in the proliferation, bioviscoelastic properties and expression levels of TGF- $\beta 1$ in lung fibroblasts, which in turn affects the transcription and translation of collagen I genes, resulting in changes in collagen expression in lung tissue and leading to remodeling of lung tissue. The present study provides further in-depth information for the early prevention and treatment of ARDS ventilator-induced lung injury and lung structural remodeling from a mechanobiology perspective and provides cell-level laboratory evidence for the implementation of a pulmonary protective ventilation strategy.

\section{Acknowledgements}

Not applicable.

\section{Funding}

This study was funded by the Lianyungang City Science and Technology Plan Funding Project (grant no. SH1601).

\section{Availability of data and materials}

The datasets used and/or analyzed during the current study are available from the corresponding author on reasonable request. 


\section{Authors' contributions}

XL conceived and designed the present study. YX and YQ performed the experiments. YX and YW analyzed the data. $\mathrm{KL}$ provided the reagents, materials and analysis tools and interpreted the data. YX and YQ wrote the manuscript. All authors read and approved the final manuscript.

\section{Ethics approval and consent to participate}

Not applicable.

\section{Patient consent for publication}

Not applicable.

\section{Competing interests}

The authors declare that they have no competing interests.

\section{References}

1. Hu HH, Chen DQ, Wang YN, Feng YL, Cao G, Vaziri ND and Zhao YY: New insights into TGF- $\beta /$ Smad signaling in tissue fibrosis. Chem Biol Interact 292: 76-83, 2018.

2. Nieman GF, Satalin J, Andrews P, Aiash H, Habashi NM and Gatto LA: Personalizing mechanical ventilation according to physiologic parameters to stabilize alveoli and minimize ventilator induced lung injury (VILI). Intensive Care Med Exp 5: 8, 2017.

3. Bates $\mathbf{J}$ and Smith BJ: Ventilator-induced lung injury and lung mechanics. Ann Transl Med 6: 378, 2018.

4. Gattinoni L, Marini JJ, Collino F, Maiolo G, Rapetti F, Tonetti T, Vasques $F$ and Quintel M: The future of mechanical ventilation: Lessons from the present and the past. Crit Care 21: 183, 2017.

5. Souma K, Shichino S, Hashimoto S, Ueha S, Tsukui T, Nakajima T, Suzuki HI, Shand FHW, Inagaki Y, Nagase T and Matsushima K: Lung fibroblasts express a miR-19a-19b-20a sub-cluster to suppress TGF- $\beta$-associated fibroblast activation in murine pulmonary fibrosis. Sci Rep 8: 16642, 2018.

6. Lv Z, Wang Y, Liu YJ, Mao YF, Dong WW, Ding ZN, Meng GX, Jiang L and Zhu XY: NLRP3 inflammasome activation contributes to mechanical stretch-induced endothelial-mesenchymal transition and pulmonary fibrosis. Crit Care Med 46: e49-e58, 2018.

7. Livak KJ and Schmittgen TD: Analysis of relative gene expression data using real-time quantitative PCR and the 2(-Delta Delta C(T)) method. Methods 25: 402-408, 2001.
8. Xie Y, Wang M, Cheng M, Gao Z and Wang G: The viscoelastic behaviors of several kinds of cancer cells and normal cells. J Mech Behav Biomed Mater 91: 54-58, 2019.

9. Wang $\mathrm{G}$ and Chen W: Effects of mechanical stimulation on viscoelasticity of rabbit scleral fibroblasts after posterior scleral reinforcement. Exp Biol Med (Maywood) 237: 1150-1154, 2012.

10. Xie Y, Liu X, Wang S, Wang M and Wang G: Proper mechanical stimulation improve the chondrogenic differentiation of mesenchymal stem cells: Improve the viscoelasticity and chondrogenic phenotype. Biomed Pharmacother 115: 108935, 2019.

11. Maca J, Jor O, Holub M, Sklienka P, Burša F, Burda M, Janout V and Ševčík P: Past and present ARDS mortality rates: A systematic review. Respir Care 62: 113-122, 2017.

12. Pais FM, Sinha P, Liu KD and Matthay MA: Influence of clinical factors and exclusion criteria on mortality in ARDS observational studies and randomized controlled trials. Respir Care 63: 1060-1069, 2018.

13. Wang X, Lai R, Su X, Chen G and Liang Z: Edaravone attenuates lipopolysaccharide-induced acute respiratory distress syndrome associated early pulmonary fibrosis via amelioration of oxidative stress and transforming growth factor- $\beta 1 / \mathrm{Smad} 3$ signaling. Biochem Biophys Res Commun 495: 706-712, 2018.

14. Yen S, Preissner M, Bennett E, Dubsky S, Carnibella R, O'Toole R, Roddam L, Jones H, Dargaville PA, Fouras A and Zosky GR: The link between regional tidal stretch and lung injury during mechanical ventilation. Am J Respir Cell Mol Biol, 2018.

15. Shimbori C, Upagupta C, Bellaye PS, Ayaub EA, Sato S, Yanagihara T, Zhou Q, Ognjanovic A, Ask K, Gauldie J, et al: Mechanical stress-induced mast cell degranulation activates TGF- $\beta 1$ signalling pathway in pulmonary fibrosis. Thorax 74 : 455-465, 2019.

16. White ES: Lung extracellular matrix and fibroblast function. Ann Am Thorac Soc 12 (Suppl 1): S30-S33, 2015.

17. Erdogan B and Webb DJ: Cancer-associated fibroblasts modulate growth factor signaling and extracellular matrix remodeling to regulate tumor metastasis. Biochem Soc Trans 45: 229-236, 2017.

18. Wu Y, Zhuang J, Zhao D, Zhang F, Ma J and Xu C: Cyclic stretch-induced the cytoskeleton rearrangement and gene expression of cytoskeletal regulators in human periodontal ligament cells. Acta Odontol Scand 75: 507-516, 2017.

19. Bartolák-Suki E, Imsirovic J, Nishibori Y, Krishnan R and Suki B: Regulation of mitochondrial structure and dynamics by the cytoskeleton and mechanical factors. Int J Mol Sci 18: E1812, 2017.

20. Manou D, Caon I, Bouris P, Triantaphyllidou IE, Giaroni C, Passi A, Karamanos NK, Vigetti D and Theocharis AD: The complex interplay between extracellular matrix and cells in tissues. Methods Mol Biol 1952: 1-20, 2019.

This work is licensed under a Creative Commons Attribution-NonCommercial-NoDerivatives 4.0 International (CC BY-NC-ND 4.0) License. 